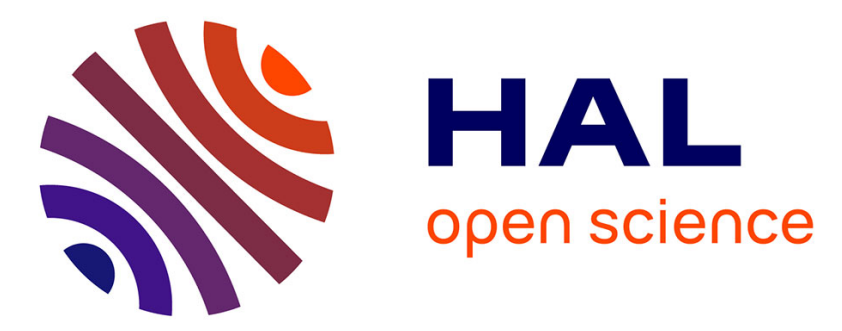

\title{
High resolution thermoplastic rapid manufacturing using injection moulding with SU-8 based silicon tools
}

\author{
Chantal Khan Malek, Laurent Robert, Gérard Michel, Akanksha Singh, \\ Mohamed Lakdhar Sahli, Gauthier Manuel
}

\section{- To cite this version:}

Chantal Khan Malek, Laurent Robert, Gérard Michel, Akanksha Singh, Mohamed Lakdhar Sahli, et al.. High resolution thermoplastic rapid manufacturing using injection moulding with SU-8 based silicon tools. CIRP Journal of Manufacturing Science and Technology, 2011, 4 (4), pp.382-390. 10.1016/j.cirpj.2011.04.001 . hal-02300191

\section{HAL Id: hal-02300191 \\ https://hal.science/hal-02300191}

Submitted on 20 Nov 2019

HAL is a multi-disciplinary open access archive for the deposit and dissemination of scientific research documents, whether they are published or not. The documents may come from teaching and research institutions in France or abroad, or from public or private research centers.
L'archive ouverte pluridisciplinaire $\mathbf{H A L}$, est destinée au dépôt et à la diffusion de documents scientifiques de niveau recherche, publiés ou non, émanant des établissements d'enseignement et de recherche français ou étrangers, des laboratoires publics ou privés. 


\title{
High resolution thermoplastic rapid manufacturing using injection moulding with SU-8 based silicon tools
}

\author{
C. Khan Malek*, L. Robert, G. Michel, A. Singh, M. Sahli, B. Gauthier Manuel \\ Institute FEMTO-ST ${ }^{1}$, CNRS UMR 6174, 32 Av. de l'Observatoire, 25044 Besançon, France
}

\begin{abstract}
The present work focuses on developing cost-efficient, fast and precise tooling for prototyping and smallseries manufacture of polymer chips using injection moulding. Exchangeable mould inserts were manufactured on thick silicon wafers patterned using SU-8 negative epoxy-based resist. First masters with feature size from a few tens to hundreds of micrometers were produced in SU-8 photoresist by contact photolithography. Polypropylene (PP), cyclo-olefin-co-polymer (COC) and polymethylmethacrylate (PMMA) were used as the injection moulding materials. A study of the PP parts was carried out using scanning mechanical microscopy (SMM) and scanning electron microscopy (SEM). In addition, submicronic features $(500 \mathrm{~nm})$ were replicated in PP from a tool patterned by e-beam lithography.
\end{abstract}

\section{Introduction}

While manufacturing durable moulds in metals and alloys is the mainstream for micro-replication technologies such as microinjection moulding, it requires rather complex and time consuming processes, and it is therefore expensive. The need for accessible, flexible and low-cost tooling is particularly relevant for prototyping and manufacturing small series of polymeric parts, especially at the laboratory level. This involves multiple challenges. First, the tool must be produced rapidly and at low cost. Second, the machinability of the insert material and especially the quality of inner surfaces such as surface roughness and sidewall draft angle are important for good replication and demoulding, particularly for smaller features where interfacial effects become dominant with the increase of surface/volume ratio. Third, the tool needs to be mounted easily on the injection moulding machine and exchanged rapidly. Fourth, it must be robust enough to survive a few tens to a few hundreds cycles to produce parts in sufficient numbers for testing. Additional attributes required for mould insert are thermal shock resistance and thermal conductivity. A further challenge is to develop a process that is extendable in term of pattern features to submicronic and nanometric scales.

\footnotetext{
* Corresponding author at: Institute FEMTO-ST, CNRS-UMR 6174, Dept. Micro Nano Sciences \& Systems, 32 Avenue de l'Observatoire, 25044 Besançon Cedex, France. Tel.: +33 381853999; fax: +33 381853998 .

E-mail address: chantal.khan-malek@cnrs-dir.fr (C. Khan Malek).

${ }^{1}$ http://www.femto-st.fr/.
}

One solution which is developed in this work is to use silicon wafers as exchangeable mould inserts that are patterned by clean room technologies. More specifically, we developed a process to manufacture micronic and submicronic SU-8 features on silicon based tools for micro-injection moulding.

Silicon has been traditionally the major material used in MEMS. Defining the patterns on mould insert using materials and techniques used in clean room for well-established microelectronics and microsystem applications (mainly MEMS and MOEMS), has a number of advantages. In particular, contact photolithography enables the collective manufacture of microstructures into a number of photoresists, i.e. parallel pattern transfer from mask into resist, with any pattern geometry in 2D, relatively high resolution (down to a few micrometers), well-defined contours and smooth sidewalls. Electron beam lithography is a direct write technique which allows manufacturing submicronic to nanometric features in electron beam sensitive resists.

SU-8 is a negative tone photosensitive resist optimized for ultraviolet photolithography and the most popular resist in microsystem technologies. Its very high optical transparency and high contrast for light above $360 \mathrm{~nm}$ wavelength make it ideally suited for applications with high aspect ratio (ratio of height over width) and nearly vertical sidewalls in very thick layers [1]. It has good qualities for a structural material, is mechanically strong when cross-linked and its epoxy base provides the chemical and thermal stability for the patterned structures. SU-8 resist is also known to be electron beam sensitive and therefore can be patterned using electron-beam lithography. A minimum linewidth of $250 \mathrm{~nm}$ was reported by Bogdanov [2]. The advantage of SU-8 
resist is therefore that it can be used with both standard photolithography and e-beam lithography, allowing to extend the process range developed with SU-8 to submicronic feature size. It also allows potentially employing mix and match technology (hybrid fabrication) with the larger features being produced by photolithography and the smallest ones by electron-beam lithography on the same wafer.

Edwards et al. was the first to demonstrate the use of SU-8/Si mould inserts for injection moulding. They produced 8-22 replicas in two common thermoplastic polymers, amorphous polycarbonate (PC) and semi-crystalline polypropylene (PP), using metallized SU-8 patterns on silicon wafers as inserts [3]. More recently, Steigert et al. fabricated polymer replicas of COC using an epoxy master with $\mathrm{Al}$ powder made by casting without any degradation of the pattern for more than 200 cycles [4]. Finally, more than 300 replicas of $\mathrm{COC}$ were produced by Hansen et al. using photolithographically patterned SU-8 on robust nickel mould insert base [5].

We report here on our processes for manufacturing SU-8/Si mould inserts and first experiments in using them for injectionmoulding of polymer parts. Polypropylene (PP) was used for the test structures as it is one of the most commonly used polymer for injection moulding due to its good fluidity at high temperature. A study of PP replicas was conducted using scanning mechanical microscopy (SMM) and scanning electron microscopy (SEM). Injection moulding of microstructures was then carried out in two thermoplastic polymers largely employed in the manufacture of microfluidic devices, PMMA and COC. Finally, we investigated mould making with submicronic patterning using electron beam lithography and its replication in PP.

\section{Experimental}

\subsection{Patterned Si mould insert and tool}

\subsubsection{SU-8 patterning for mould insert}

Ideally producing a mould insert with slightly inclined mould walls, that is an inward taper of a few degrees from the base to the top (positive draft angle), facilitates demoulding of the injected parts. However, realizing such sloped sidewalls with SU-8 proved very difficult so the objective was to obtain structures with sidewalls as vertical as possible. Additional challenges concern a good adherence of the SU-8 micropatterns to the silicon base plate which might be affected by various factors such as: (1) internal stress buildup (for which SU-8 is known) during processing, which includes effect of mismatch between thermal expansion coefficient of crosslinked SU-8/Si substrate $\left(50 \times 10^{-6} \mathrm{~K}^{-1}\right.$ vs. $\left.4.68 \times 10^{-6} \mathrm{~K}^{-1}\right)$ causing adhesion loss between SU-8 and $\mathrm{Si}$; (2) large shear forces exerted on the SU-8 microstructures by the flow of melted polymer during the filling of the cavity in the injection step; (3) tearing of the patterns that may occur due to the friction forces between the mould insert and polymer replica during the demoulding step.

The adherence of the SU- 8 patterns is improved by using a twolayer process. A first layer of SU-8 (approximately $50 \mu \mathrm{m}$ thick) was spin-coated on the virgin wafer and blank-exposed on its whole surface. The second layer of SU-8, which defines the patterns, was spin coated with the desired thickness (from $25 \mu \mathrm{m}$ to $100 \mu \mathrm{m}$ thick) on top of the first layer, and patterned by contact UV photolithography. The first SU-8 unpatterned coating served to increase the adhesion for the second SU-8 layer in which the micrometric-size patterns were formed. Preliminary experiments without this first layer revealed systematic destruction of the patterns of the mould insert during the demoulding. Then, the adhesion of each SU-8 layer is increased by exposing the surface to oxygen plasma before dispensing the resist (i.e. the silicon substrate for the first SU-8 layer step and the first SU-8 layer for the second SU-8 layer step). Finally, both SU-8 layers are exposed and polymerized by following strictly the SU-8 datasheet corresponding to the SU-8 2075 formulation [6]. In particular, the UV exposure is conducted using the recommended long pass filter (PL-360-LP from Omega Optical) to obtain vertical sidewalls. Finally, a hard bake $\left(200{ }^{\circ} \mathrm{C}\right.$ during $\left.1 \mathrm{~h}\right)$ is added to ensure further crosslinking so that SU-8 properties do not change in actual use during the injection moulding process. Additionally, the resist pattern lines and sidewalls obtained with the lithographic process were smooth and suitable for good replication.

The layout of the mask for the trial mould was made in such a way that the patterns were evenly distributed over the surface. The ridges (inverse of channels) were $30 \mathrm{~mm}$ long and their width covered the range: $25,50,100,150,200,250,300$ to $400 \mu \mathrm{m}$. They were ended by pillars (inverse of reservoirs) of $2 \mathrm{~mm}$ diameter. The maximum aspect ratio investigated in these experiments was 4 obtained with a $90 \mu \mathrm{m}$ thick SU-8 photoresist and $25 \mu \mathrm{m}$ feature size. The distance separating the ridges was chosen large enough $(3 \mathrm{~mm})$ so that the polymer could flow well during injection moulding.

The overall time used to process a SU-8/Si mould insert with photolithography was around $10 \mathrm{~h}$ which encompasses patterning the optical mask by laser pattern generator, the two-layer SU-8 process with oxygen plasma treatment, the UV exposure step followed by hard bake. In comparison, for feature size above $100 \mu \mathrm{m}$, the manufacture of such an insert in metal by milling would take around 1 day including CAD software and CNC machining. However, the minimum feature size on the SU-8 mould insert was $25 \mu \mathrm{m}$, and it could be further reduced to a few micrometers still using standard contact photolithography, which would be very difficult to achieve, if not impossible, using a standard micromilling process. The manufacture of such silicon mould insert for feature size in the range $100 \mu \mathrm{m}$ - to a few micrometers is therefore very competitive with mechanical micromachining in term of time to produce the insert. In addition, the clean room process can be extended further towards smaller dimensions but at the cost of time.

Concerning the generation of submicronic features, patterning was performed using electron-beam lithography in SU-8 resist, which allowed reaching a resolution down to $100 \mathrm{~nm}$. A $600 \mathrm{~nm}$ SU-8 resist layer was spin-coated on a thick silicon wafer using SU2002 resist (Microchem) mixed with its thinner in a ratio 1:0.5, followed by a baking step at $95{ }^{\circ} \mathrm{C}$ during $1 \mathrm{~min}$. The electron beam exposure was conducted with a Raith E-Line system. The best doses (around $2 \mu \mathrm{C} / \mathrm{Cm}^{2}$ ) were selected depending of the size and of the pitch of the features. The patterning speed was $20 \mathrm{~min} / \mathrm{mm}^{2}$ for feature size ranging from $1 \mu \mathrm{m}$ to $100 \mathrm{~nm}$. After a postbake of 2 min at $95^{\circ} \mathrm{C}$, the resist was developed in Propylene Glycol Methyl Ether Acetate (PGMEA, same developer used for the photolithographic process) during $10 \mathrm{~min}$.

Producing a mould insert using electron beam lithography employs a direct patterning method (without a mask). It has the advantage of using a standard tool developed for generation of the micronic, submicronic, and nanoscale geometries, allowing flexible pattern design, highly automated and precisely controlled operation (like accurate positioning). Though relatively slow, the throughput of electron beam lithography is competitive with proximal probe-based writing techniques such as atomic force microscopy (AFM), scanning tunneling microscopy (STM), dip-pen lithography (DPL), near-field scanning optical microscopy (NSOM), and apertureless near-field scanning optical microscopy (ANSOM), especially if they are used in a non parallel scheme.

\subsubsection{Mould tool and inserts}

The mould tool that was developed consists of mould base plates screwed to a standard steel mould tool of a conventional injection moulding machine (see paragraph on injection moulding) so that they could be mounted and changed easily (Figs. 1 and 2). In 

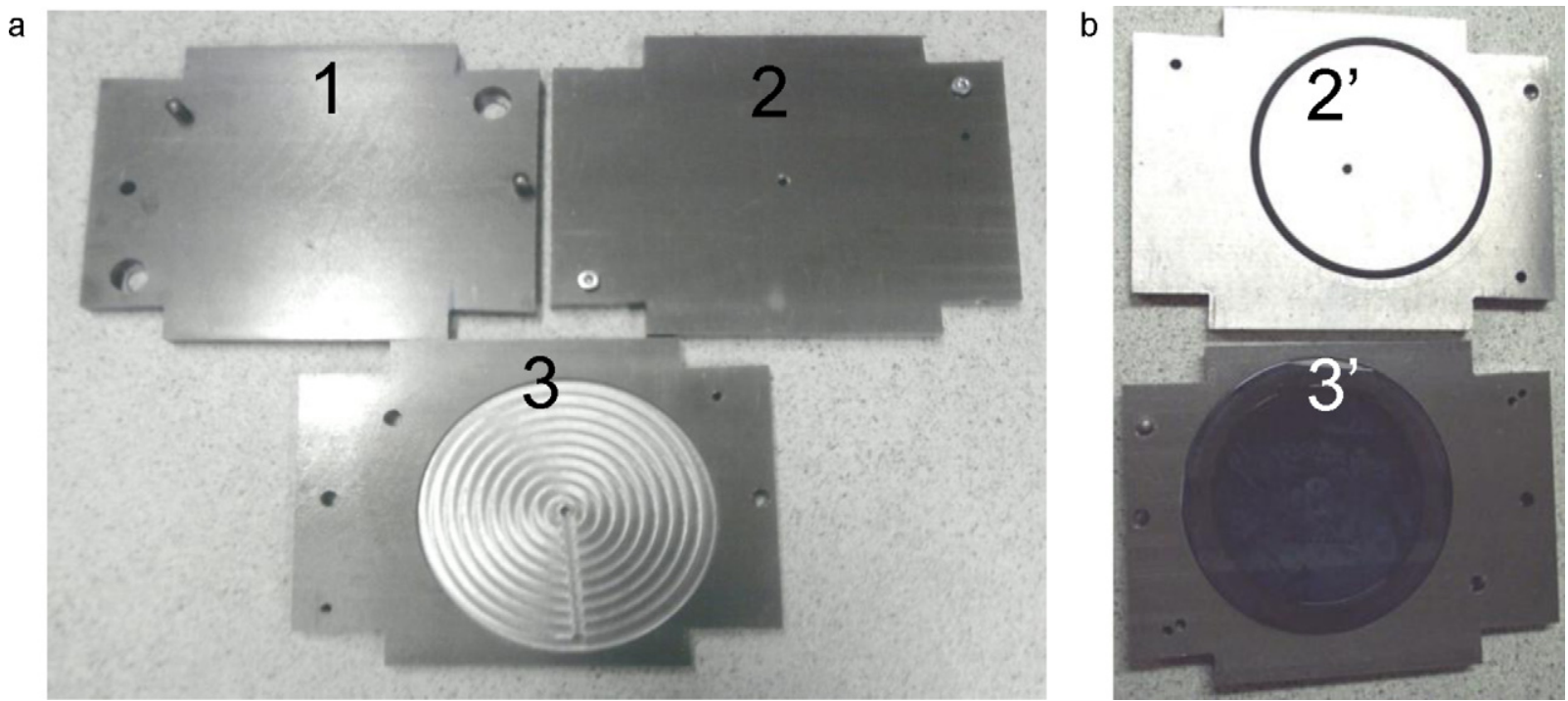

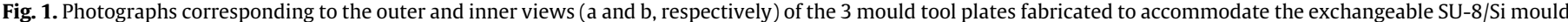

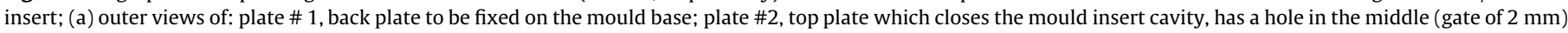

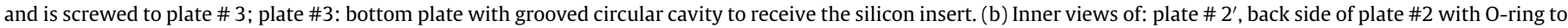
close the mould insert cavity; plate \#3', same as plate \#3 with SU-8/Si mould insert in place.

one of the plate, a circular cavity was mechanically machined to receive an interchangeable silicon wafer as a mould insert. This base plate supports the micro-structured SU-8/Si mould insert and reinforces its mechanical stability.

In the first set of experiments (PP with test structures), threeinch (400 $\mu \mathrm{m}$ thick) wafers were used as mould insert substrates. The brittleness of the silicon was not an issue when closing the mould as it closes not on the fragile silicon wafer insert but on the metallic robust mould base. However, resistance of the wafer to plastic flow and compression during injection of the polymer was an issue so the thin silicon wafer was glued (with loctite 430) to a metallic plate of same radius, which was itself screwed in one of the brass back plates to avoid movement (lifting). However, this set-up had the disadvantage of not allowing an exchange of the silicon wafers flexible enough. The mould insert tool was therefore redesigned to accomodate easily exchangeable thick and flat silicon substrates $(1.5 \mathrm{~mm}$-thick double-sided polished 4 -in. silicon wafers) as mould inserts and eliminate the additional step of glueing or screwing used in the first set-up. The new set-up consists of three plates (numbered $1-3$ in Fig. $1 \mathrm{a}$ and $2^{\prime}$ and $3^{\prime}$ in
Fig. 1b) that could be maintained inside the mould cavity by the locking mechanism (using a rubber O-ring) of the injection moulding machine. When demoulding parts, Plates $2 / 2^{\prime}$ and $3 / 3^{\prime}$ are removed. Possibility for variation of thickness of the replica was also included by placing the patterned silicon substrate on interchangeable steel plates or silicon wafers of the same radius.

\subsection{Micro-injection moulding}

\subsubsection{Materials}

Polypropylene (PP), a semi crystalline polymer, was chosen for the first injection moulding tests because it is known for its good fluidity and replication ability. We used two different grades, a heterophasic copolymer (Moplen EP548 N from Basell) and one polypropylene random copolymer, modified by ethylene (PPRA12MN40 from Sabic ${ }^{\mathbb{R}}$ ). Other polymers investigated in this work were two common optically clear amorphous thermoplastic polymers used as substrates in bio MEMS applications, COC and PMMA. We chose two grades, COC $^{\circledR}$ Topas 8007 (from Ticona $\mathrm{GmbH}$ ) and Plexiglass ${ }^{\circledR}, 6 \mathrm{~N}$ (from Evonik Degussa GmbH). Table 1

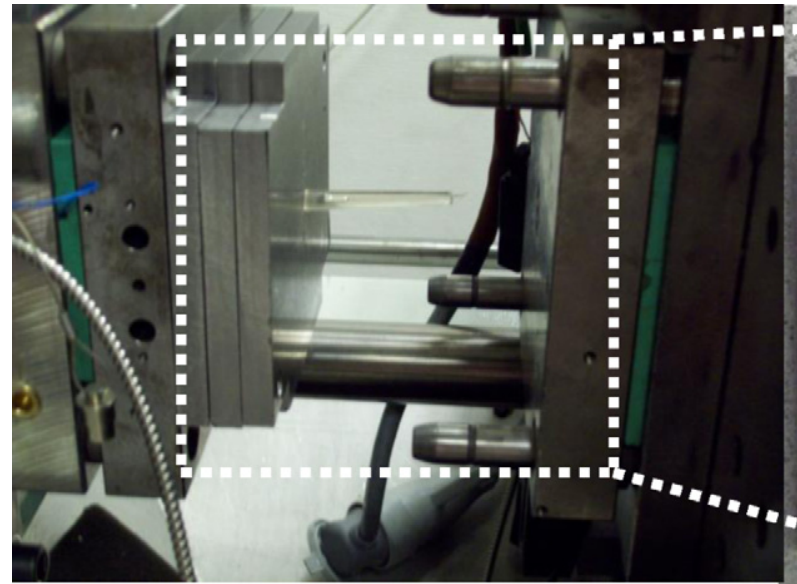

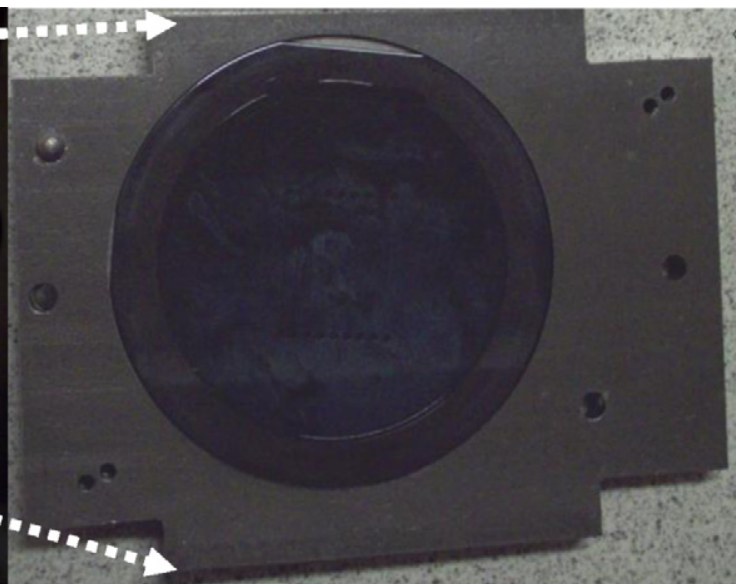

b

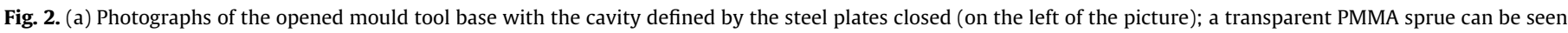
sticking out of this closed cavity. (b) Mould plate \#3 with the SU-8/Si mould insert placed on it (picture similar to picture \#3'). 
Table 1

Material properties of polymers (from datasheets of manufacturers) used for injection moulding along with characteristics of SU-8 photoresist [7].

\begin{tabular}{|c|c|c|c|c|c|}
\hline Material properties & $\begin{array}{l}\text { PP (Moplen EP548 N, } \\
\text { Basell) }\end{array}$ & $\begin{array}{l}\text { PP (RA12MN40, } \\
\text { Sabic) }\end{array}$ & $\begin{array}{l}\text { COC } \text { (Topas }^{\circledR} 8007 \text {, } \\
\text { Ticona GmbH) }\end{array}$ & $\begin{array}{l}\text { PMMA (Plexiglasss }{ }^{\mathbb{R}} \text {, } \\
6 \text { N, Evonik Degussa GmbH) }\end{array}$ & SU-8 (Microchem) \\
\hline Mass density $\left(\mathrm{g} / \mathrm{cm}^{3}\right)$ & 0.9 & 0.9 & 1.02 & 1.19 & 1.19 \\
\hline Modulus (MPa) & 1400 & 1200 & 2600 & 3200 & 4020 \\
\hline Tensile test-stress at yield (MPa) & 27 & 32 & 63 & 67 & 34 \\
\hline Strain at break (\%) & $>50$ & $>50$ & 10 & 3 & Data not available \\
\hline $\begin{array}{l}\text { Charpy impact strength notched } \\
\left(\mathrm{kJ} / \mathrm{m}^{2}\right) \text { at } 23{ }^{\circ} \mathrm{C}\end{array}$ & 8 & 3.3 & 20 & 20 & Data not available \\
\hline $\begin{array}{l}\text { Glass transition temperature } T_{\mathrm{g}} \\
\text { for amorphous regions }\left({ }^{\circ} \mathrm{C}\right)\end{array}$ & Data not available & Data not available & 78 & 99 & 200 \\
\hline $\begin{array}{l}\text { Coefficient of linear thermal } \\
\text { expansion }\left(10^{-6} \mathrm{~K}^{-1}\right)\end{array}$ & Data not available & Data not available & 70 & 80 & 50 \\
\hline Melt flow index (MFI) (g/10 min) & {$\left[230^{\circ} \mathrm{C} / 2.16 \mathrm{~kg}\right]: 12$} & {$\left[230^{\circ} \mathrm{C} / 2.16 \mathrm{~kg}\right]: 40$} & {$\left[260^{\circ} \mathrm{C} / 2.16 \mathrm{~kg}\right]: 32$} & {$\left[230^{\circ} \mathrm{C} / 3.8 \mathrm{~kg}\right]: 12$} & Data not available \\
\hline
\end{tabular}

summarizes the properties of the thermoplastic polymer grades used in the injection moulding experiments.

\subsubsection{Injection moulding}

Injection moulding was conducted using an Arburg $^{\odot}$ Allrounder (220S/150-35) which is not optimized for micromoulding. The diameter of the plastification screw is $15 \mathrm{~mm}$. The machine allows a maximum closing strength force of $50 \mathrm{kN}$ and a maximum injection rate of $760 \mathrm{~mm} / \mathrm{s}$. The thermoplastic polymers were injected in the mould through an injection gate of $2 \mathrm{~mm}$. The tests were carried out starting with the standard conditions recommended by the manufacturers of the polymers. The parameters varied to optimize injection moulding of the parts were the volume dosage, melt temperature, and mould temperature.

The volume dosage was first determined to fill the volume of the mould cavity (on the order of $7 \mathrm{~cm}^{3}$ of material). The melt temperature was first varied stepwise (in steps of $10^{\circ} \mathrm{C}$ ) to optimize the filling of the microfeatures of the mould insert cavity before solidification of the polymer melt occurs. In order to overcome flow resistance, high injection speed and high injection pressure are preferred, since the resulting high shear rate is good for viscous heating and decreasing polymer viscosity. The injection rate was increased progressively up to its final value set close to the maximum value. The injection pressure varied stepwise (in steps of $10 \mathrm{MPa}$ ) up to its final value, which was high though not at the maximum to minimize compression force on the silicon mould insert. An appropriate holding time at constant pressure was selected to ensure proper packing of the polymer in the microcavities of the mould insert. Good filling was obtained for PP with a mould at room temperature whereas the replication quality was improved for COC and PMMA replicas by injecting into a heated mould so that the injected melt does not freeze prematurely on the walls of the microcavity. After solidification of the polymer part inside the mould upon cooling, the replica is manually separated from the mould for the three polymers. The optimized values of the moulding parameters for injecting the various polymers with our mould inserts are summarized in Table 2.

\section{Results and discussions}

\subsection{Topography of PP test replicas}

Polymers parts of $500 \mu \mathrm{m}$ thickness were produced in PP (Basel) using a SU-8/Si mould insert with a patterned SU-8 layer of $50 \mu \mathrm{m}$ thickness (maximum aspect ratio of structures of 2 ). To assess the filling of the SU-8/Si mould insert and the dimensional and geometrical quality of replication, 2D profile measurements were carried out on the PP replicas of using scanning mechanical microscopy (SMM). The apparatus used is a tactile profilometer with a conical probe in diamond with a tip radius of $2 \mu \mathrm{m}$ and a cone angle of $45^{\circ}$ [8].

The evolutions of the channel profiles of the injected PP replicas were recorded along the XX direction. The recessed profiles of the replica were quasi-equivalent to the nominal inverted profile of both studied inserts for channel widths between $100 \mu \mathrm{m}$ and $500 \mu \mathrm{m}$. This could not be verified for channels with width lower than $80 \mu \mathrm{m}$ as the tip of the SMM probe was too large to enter into them. Fig. 3 illustrates some graphs produced with lines with different widths.

One needs to point out that the sloped shapes of the cavity sidewalls observed in Fig. 3 are due to the conical shape of the tactile probe (i.e. probe convolution effect). In reality these wall profiles are almost vertical as will be seen on the SEM pictures of Figs. 7-10 (see Section 3.3).

The dimensions (width and depth) of channels of the replicas produced in PP (Basel) were measured on a batch of ten pieces at two different locations on the chip in the middle of the channel length and at one extremity of the channel length (just before the reservoir). The depth value was measured with SMM whereas the top and bottom widths were measured optically at the focal plane of the microscope.

The results of the average size of the channels on the ten replicated pieces are gathered in Table $3 a$ and $b$ for the narrowest and largest channels (of nominal dimensions $h=25 \mu \mathrm{m}$; $e=25 \mu \mathrm{m}$ and $h=400 \mu \mathrm{m} ; e=25 \mu \mathrm{m}$, respectively).

Table 2

Parameters of injection utilized in the injection moulding trials conducted on the Arburg ${ }^{\odot}$ Allrounder (220S/150-35) machine.

\begin{tabular}{|c|c|c|c|c|}
\hline Material & $\begin{array}{l}\text { PP (Moplen } \\
\text { EP548N, Basel) }\end{array}$ & $\begin{array}{l}\text { PP (RA12MN40, } \\
\text { Sabic) }\end{array}$ & $\begin{array}{l}\text { COC }(8007, \\
\left.\text { TOPASs }^{(\mathbb{R})}\right)\end{array}$ & $\begin{array}{l}\text { PMMA (Plexiglasss }{ }^{\mathbb{B}} \text {, } \\
6 \mathrm{~N}, \text { Evonik) }\end{array}$ \\
\hline Injection temperature $\left({ }^{\circ} \mathrm{C}\right)$ & 230 & 220 & 265 & 220 \\
\hline Flow rate $\left(\mathrm{cm}^{3} / \mathrm{s}\right)$ & 22 & 22 & 20 & 22 \\
\hline Holding pressure (MPa) & 80 & 180 & 180 & 120 \\
\hline Holding time (s) & 10 & 10 & 10 & 10 \\
\hline Mould temperature $\left({ }^{\circ} \mathrm{C}\right)$ during injection & 25 & 25 & 90 & 60 \\
\hline Mould temperature $\left({ }^{\circ} \mathrm{C}\right)$ during demoulding & 25 & 25 & $\sim 75$ & $\sim 45$ \\
\hline
\end{tabular}



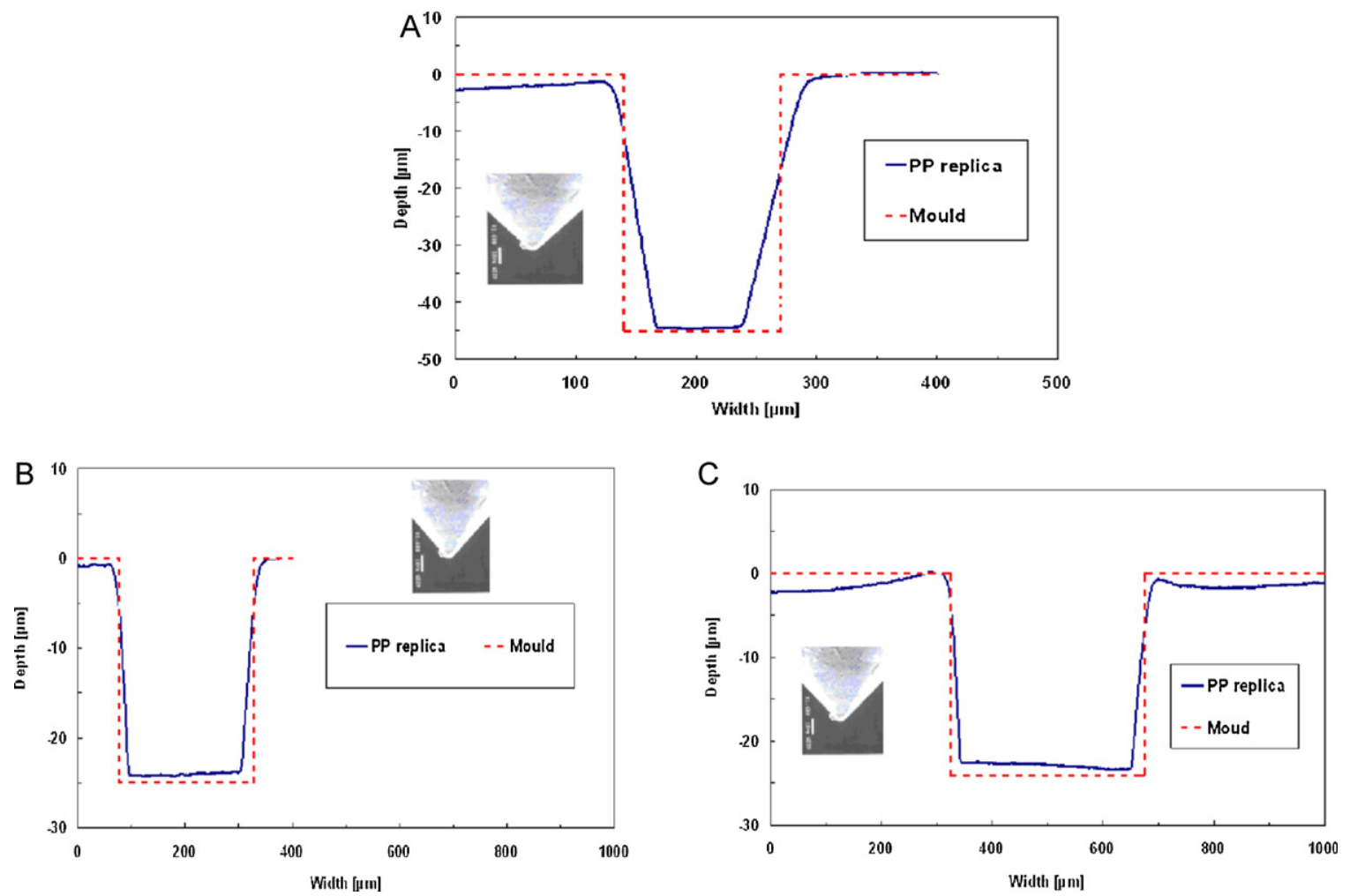

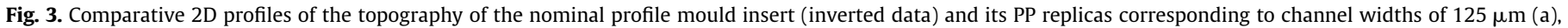
$250 \mu \mathrm{m}$ (b) and $350 \mu \mathrm{m}$ (c) recorded in the X-X direction. An image of the tip of the SMM probe used, at the same scale, is also inserted as an inset.

\subsection{Roughness of SU-8/Si mould insert and PP test replicas}

Roughness measurements were carried out using a mechanical profilometer (Tencor - Alpha Step IQ) with a diamond tip of $5 \mu \mathrm{m}$ radius operated with a scanning speed of $5 \mu \mathrm{m} / \mathrm{s}$ on a length of $1 \mathrm{~mm}$ inside and outside the reservoir pattern of $2 \mathrm{~mm}$ diameter on the mould insert and replicas produced in PP (Basel). Two different

Table 3

Average depth and widths ( $h, e_{1}$ and $e_{2}$ defined, respectively, as indicated in Fig. 4 ) of the channels located at the middle and extremity of the channel length for the narrowest channel Table 3-a and largest channel Table 3-b on the PP replicas in comparison with dimensions of corresponding ridges on the $\mathrm{Si} / \mathrm{SU}-8$ mould insert.

\begin{tabular}{|c|c|c|c|c|}
\hline & Middle & Extremity & Middle & Extremity \\
\hline \multicolumn{5}{|c|}{ (a) Narrowest channel } \\
\hline$h[\mu \mathrm{m}]$ & $25 \pm 1$ & $25 \pm 1$ & $24 \pm 1$ & $24 \pm 1$ \\
\hline$e_{1}[\mu \mathrm{m}]$ & $25 \pm 3$ & $25 \pm 3$ & $29 \pm 3$ & $27 \pm 3$ \\
\hline$e_{2}[\mu \mathrm{m}]$ & $25 \pm 3$ & $25 \pm 3$ & $27 \pm 3$ & $26 \pm 3$ \\
\hline \multicolumn{5}{|c|}{ (b) Largest channel } \\
\hline$h[\mu \mathrm{m}]$ & $25 \pm 1$ & $25 \pm 1$ & $25 \pm 1$ & $25 \pm 1$ \\
\hline$e_{1}[\mu \mathrm{m}]$ & $400 \pm 3$ & $400 \pm 3$ & $409 \pm 3$ & $407 \pm 3$ \\
\hline$e_{2}[\mu \mathrm{m}]$ & $400 \pm 3$ & $400 \pm 3$ & $405 \pm 3$ & $402 \pm 3$ \\
\hline
\end{tabular}

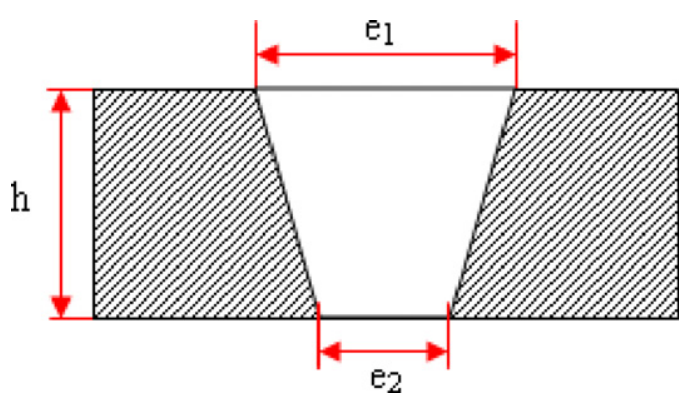

Fig. 4. Schematic of the channel cross-section indicating the depth (h), the width at the top and bottom of the channel, respectively ( $e_{1}$ and $e_{2}$, respectively). areas ( $\mathrm{a}$ and $\mathrm{b}$ ) of the SU-8/Si mould insert and PP replicas were measured as indicated in Fig. 5.

Table 4 summarizes the roughness coefficients of these measured surfaces, the arithmetical average height, the root mean square height, and the total height ( $R_{\mathrm{a}}, R_{\mathrm{q}}$ and $R_{\mathrm{t}}$, respectively) on the SU-8 mould insert and PP replica. The roughness factors $\left(R_{\text {replica, }} / \mathrm{R}_{\text {mould insert }}\right)$, as determined from measurements in area (a) and (b) respectively, are also indicated in Table 4. Ideally, if the replication process reproduces perfectly well the roughness of the mould insert, the roughness of the replica should be equal to the roughness of the mould insert and the roughness factor should be equal to 1 . In this case, the high value of the roughness ratios indicates that the replication process under the selected operative conditions does not reproduce faithfully the mould insert roughness, in particular in the areas corresponding to the microstructures of the mould insert. A decrease of those ratios can be achieved by using a higher temperature for injection moulding and mould temperature, which will decrease the viscosity of the PP polymer, hence fill better the microcavities of the mould insert.

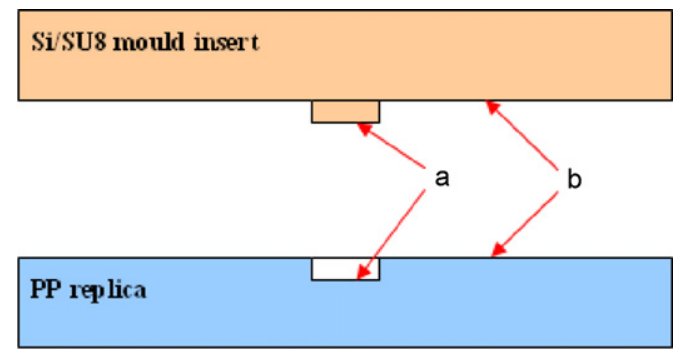

Fig. 5. Schematic representation of the mould insert and replica with the different areas measured ( $a$ and $b$ ). 
Table 4

Roughness coefficients and roughness ratios of the various surfaces measured in the areas indicated in Fig. 5.

\begin{tabular}{|c|c|c|c|c|c|c|}
\hline & \multicolumn{2}{|c|}{ Mould insert } & \multicolumn{2}{|c|}{ PP replica } & \multicolumn{2}{|c|}{$R_{\text {replica }} / R_{\text {insert }}$} \\
\hline & Area a & Area b & Area a & Area b & Area a & Area $b$ \\
\hline Arithmetical mean roughness ( $\mathrm{Ra}$ in $\mathrm{nm}$ ) & 1 & 6 & 45 & 58 & 45 & 9.7 \\
\hline Root mean square roughness ( $\mathrm{Rq}$ in $\mathrm{nm}$ ) & 1.3 & 8 & 56 & 72 & 43.1 & 9 \\
\hline Maximum peak-to-valley roughness ( $\mathrm{Rt}$ in $\mathrm{nm}$ ) & 15 & 70 & 524 & 701 & 34.9 & 10 \\
\hline
\end{tabular}

Table 5

Results in injection moulding various thermoplastic polymers using photolithographically defined SU-8/Si mould inserts.

\begin{tabular}{|c|c|c|c|c|}
\hline Injection moulding & PP (EP548N, Basel) & PP (RA12MN40, Sabic) & COC (8007, TOPAS) & PMMA (Plexiglass, df21, 6N, Evonik) \\
\hline Feature size: width $(\mu \mathrm{m}) /$ depth $(\mu \mathrm{m})$ & $25 \mu \mathrm{m}$ to $400 \mu \mathrm{m} / 50 \mu \mathrm{m}$ & $25 \mu \mathrm{m}$ to $100 \mu \mathrm{m} / 90 \mu \mathrm{m}$ & 25 to $100 \mu \mathrm{m} / 90 \mu \mathrm{m}$ & 25 to $100 \mu \mathrm{m} / 90 \mu \mathrm{m}$ \\
\hline Length of microstructure (mm) & 30 & 30 & 30 & 30 \\
\hline $\begin{array}{l}\text { Maximum aspect ratio (depth/width) } \\
\text { obtained }\end{array}$ & 2 & 3.6 & 3.6 & 3.6 \\
\hline Thickness of replica $(\mu \mathrm{m})$ & 500 & 320 & 770 & 780 \\
\hline Number of replicas & 30 & $>100$ & 20 & 20 \\
\hline
\end{tabular}

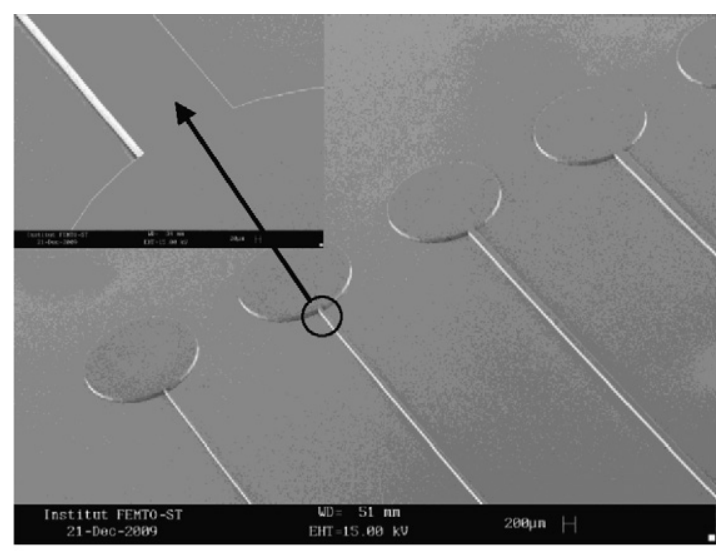

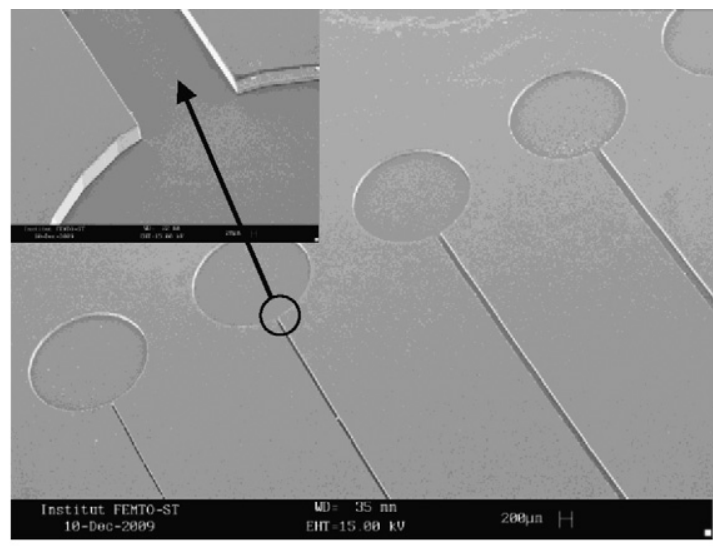

b

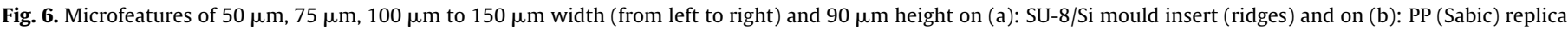

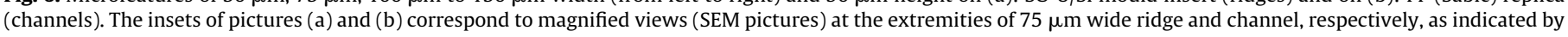
the arrows.

\subsection{Replication in thermoplastic polymers}

Injection moulding was conducted using various thermoplastic polymers. Table 5 summarizes the various replicas injectionmoulded in PP, COC and PMMA using SU-8/Si mould inserts. The feature size and length of microstructures on the mould, the thickness of polymer replicas and the number of replications performed without deterioration of the mould is also indicated in

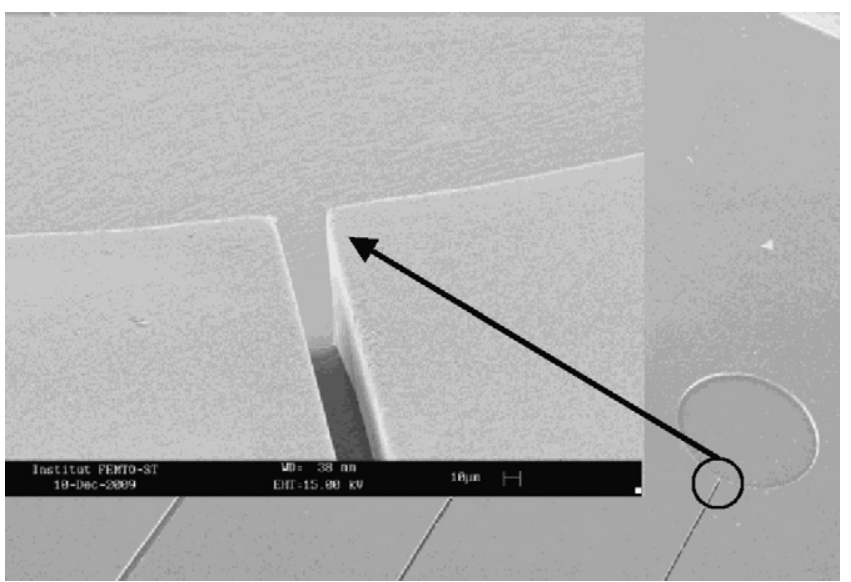

Fig. 7. SEM image of a micro-channel ( $25 \mu \mathrm{m}$ width, $90 \mu \mathrm{m}$ height) in PP (Sabic) replica; inset: magnified view of the microchannel (indicated by the arrow). this table. Flash could be seen only on the border of the replica wafer plate, but not in the central part. Quality of replicas was found to be good all along the length of the channels.

Fig. 6 represents the SEM images of a PP replica with microchannels of various widths (from $50 \mu \mathrm{m}$ to $150 \mu \mathrm{m}$ ) and $90 \mu \mathrm{m}$ depth along with the reverse pattern on the SU-8/Si mould insert. Fig. 7 shows the minimum feature size that was produced (25 $\mu \mathrm{m}$ width in $90 \mu \mathrm{m}$ height). The channel exhibits nearly vertical sidewalls.

A number of replicas largely sufficient for prototyping needs were produced successfully without deterioration of the SU-8/Si mould using PP (Sabic). The process developed was used for prototyping disposable thin PP microfluidic biochips designed for protein crystallization and analysis $[9,10]$.

COC and PMMA replicas were fabricated by using the mould insert with high aspect ratio (3.6). Demoulding of the replicas in both COC and PMMA proved more difficult as compared with PP, with $\mathrm{COC}$ the most difficult to demould. The greater brittleness and stiffness of PMMA and COC appear to be a sensitive parameter influencing the quality of replicas when demoulding manually; PMMA and COC have an elastic modulus higher than PP (a factor 2 as can be seen in Table 1 ), which results in breaking the parts if demoulding is conducted at room temperature. Therefore in our experiments, the demoulding was performed at a relatively high temperature, around $75{ }^{\circ} \mathrm{C}$ for $\mathrm{COC}$ and $45^{\circ} \mathrm{C}$ for PMMA. In these conditions, good quality of replicas was obtained for PMMA, even with the smallest feature size $(25 \mu \mathrm{m})$ as can be seen in Figs. 8 and 


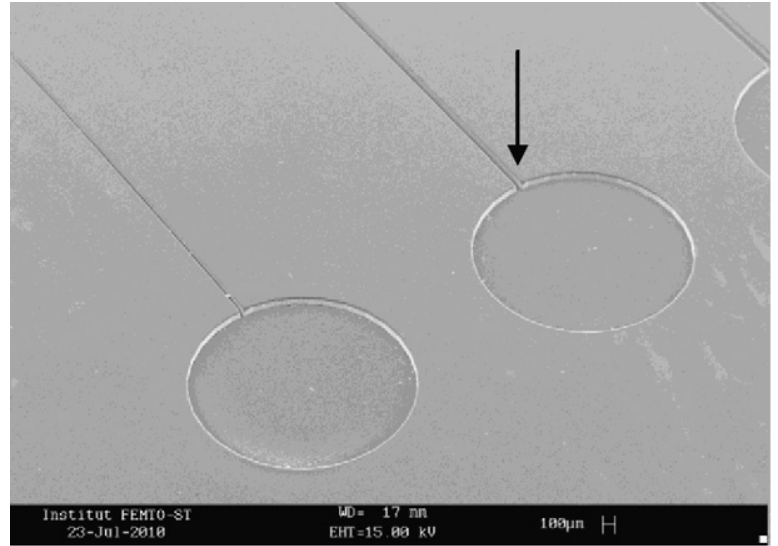

a

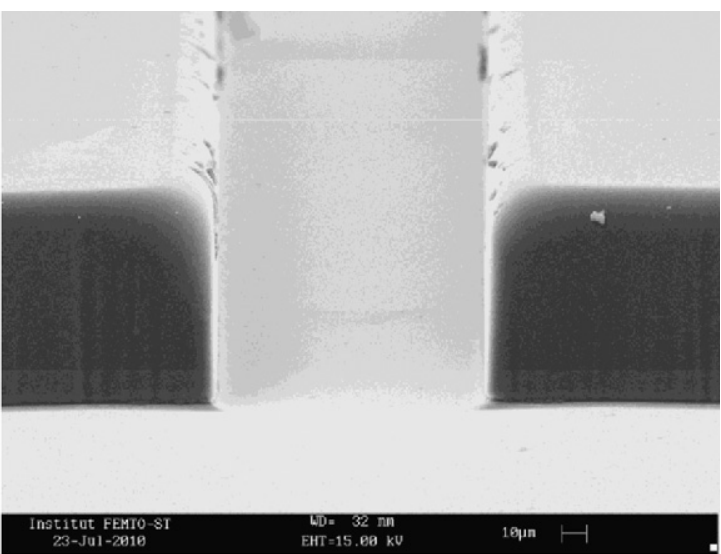

b

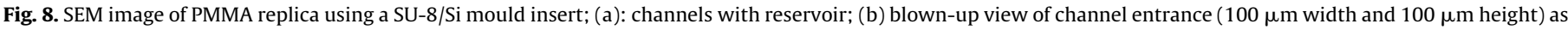
indicated by the arrow.

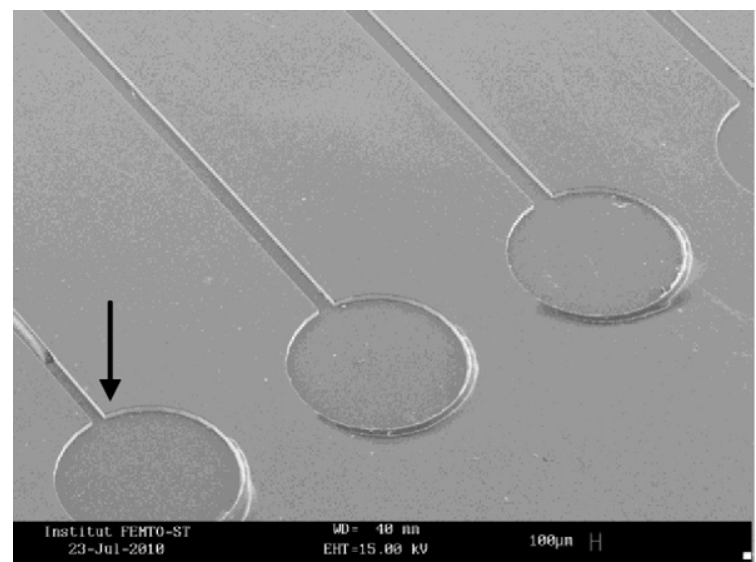

a

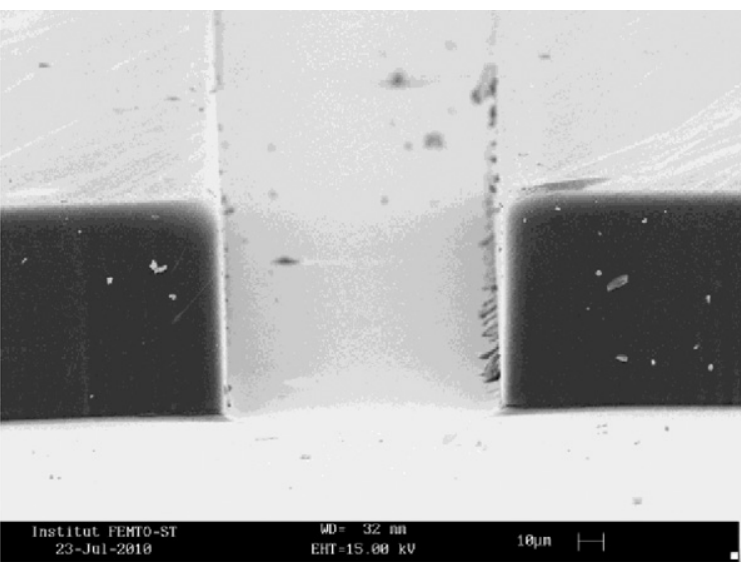

b

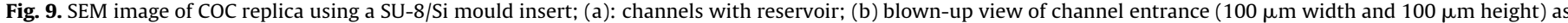
indicated by the arrow.

10a whereas this led to some defects in the COC parts, for example too much matter along the reservoir edges or in the smallest channel $(25 \mu \mathrm{m})$ as well as surfaces less smooth as compared with PMMA (as can be seen on the SEM pictures of Figs. 9 and 10b). The temperature of demoulding for COC could not be increased any further as it is already close to the glass transition temperature of $\operatorname{COC} 8007\left(\sim 75^{\circ} \mathrm{C}\right.$ vs. $\left.78^{\circ} \mathrm{C}\right)$ which already leads to pattern deformation. Due to the higher forces required to demould the parts in both PMMA and COC as compared with PP, the adherence of SU-8 layer also becomes weaker resulting in tearing out of the long ridges on the mould insert. This explains the lower number of replicas produced in PMMA and COC as compared with PP (Table 5).

Two main sources of wear for microstructured features of the SU-8 mould insert have been identified: (1) during the injection

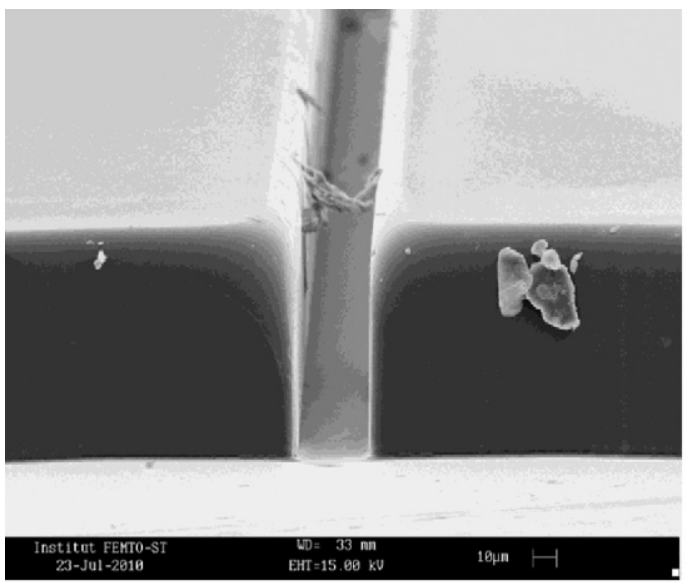

a

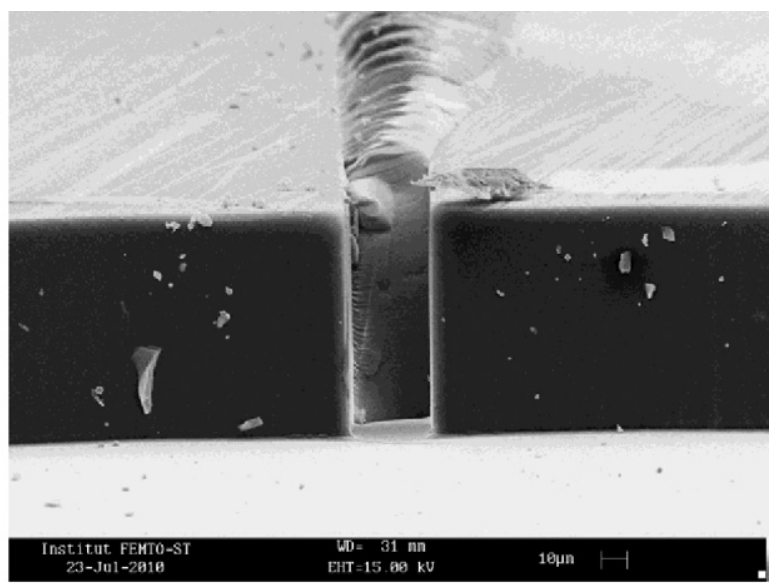

b

Fig. 10. SEM pictures of $25 \mu \mathrm{m}$ wide feature with $90 \mu \mathrm{m}$ height in PMMA (a) and COC (b). 


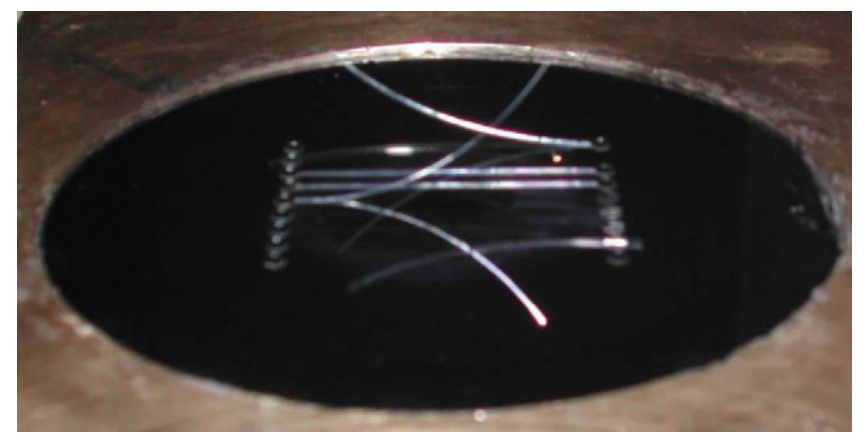

Fig. 11. Picture of the SU-8/Si mould insert with ridges of $30 \mathrm{~mm}$ length and $100 \mu \mathrm{m}$ width and height destroyed after demoulding.

moulding process, the resistance of the patterns of the mould insert to the hydrodynamical forces exerted by the melt polymer during the filling of the cavity; (2) during the demoulding step, the issues of adherence and friction between the mould insert and replica, which may cause the tearing of very long and tall ridges of aspect ratio superior to 1 . SU-8 ridges of $30 \mathrm{~mm}$ length and $100 \mu \mathrm{m}$ width and height on the mould insert were destroyed as could be observed after the demoulding step (Fig. 11).

\section{Conclusions}

Rapid manufacturing of low-cost exchangeable high resolution mould inserts for high precision injection moulding of polymer chips was developed. The processes developed were based on using thick silicon wafers which were patterned using the SU-8 negative resist.
Using SU-8 resist allows producing mould inserts with a very wide range of feature sizes, with scale from microscale to nanoscale using two different processes and clean room technologies, photolithography and electron-beam lithography, respectively.

The main results obtained in this work are the following:

- Mould inserts with microscopic features were produced in SU-8 by contact photolithography using a two-step coating process. The mould inserts were implemented on a standard injection moulding machine.

- Injection moulding tests conducted using polypropylene (PP) polymer showed good replication quality with SU-8 microstructures of $90 \mu \mathrm{m}$ height and width down to $25 \mu \mathrm{m}$, i.e. an aspect ratio of 3.6. The adherence of the SU-8 microstructures to the Si substrate was found to be adequate and the SU-8/Si mould inserts were robust enough to manufacture small series for lab purpose. In addition, a study of the PP parts was carried out using scanning mechanical microscopy (SMM) and scanning electron microscopy (SEM).

- Injection moulding of microstructures was also demonstrated on PMMA and COC, but demoulding was more difficult than for PP due to the greater brittleness and stiffness of these thermoplastics compared with PP, hence leading to a lower number of replicas produced without damaging the SU-8 mould inserts.

- Concerning the generation of submicronic features, patterning of the mould insert was performed using electron-beam lithography. Replication of submicronic features $(500 \mathrm{~nm})$ was demonstrated in PP.

The processes developed to manufacture SU-8 features on silicon based tools with feature size ranging from hundreds of micrometers
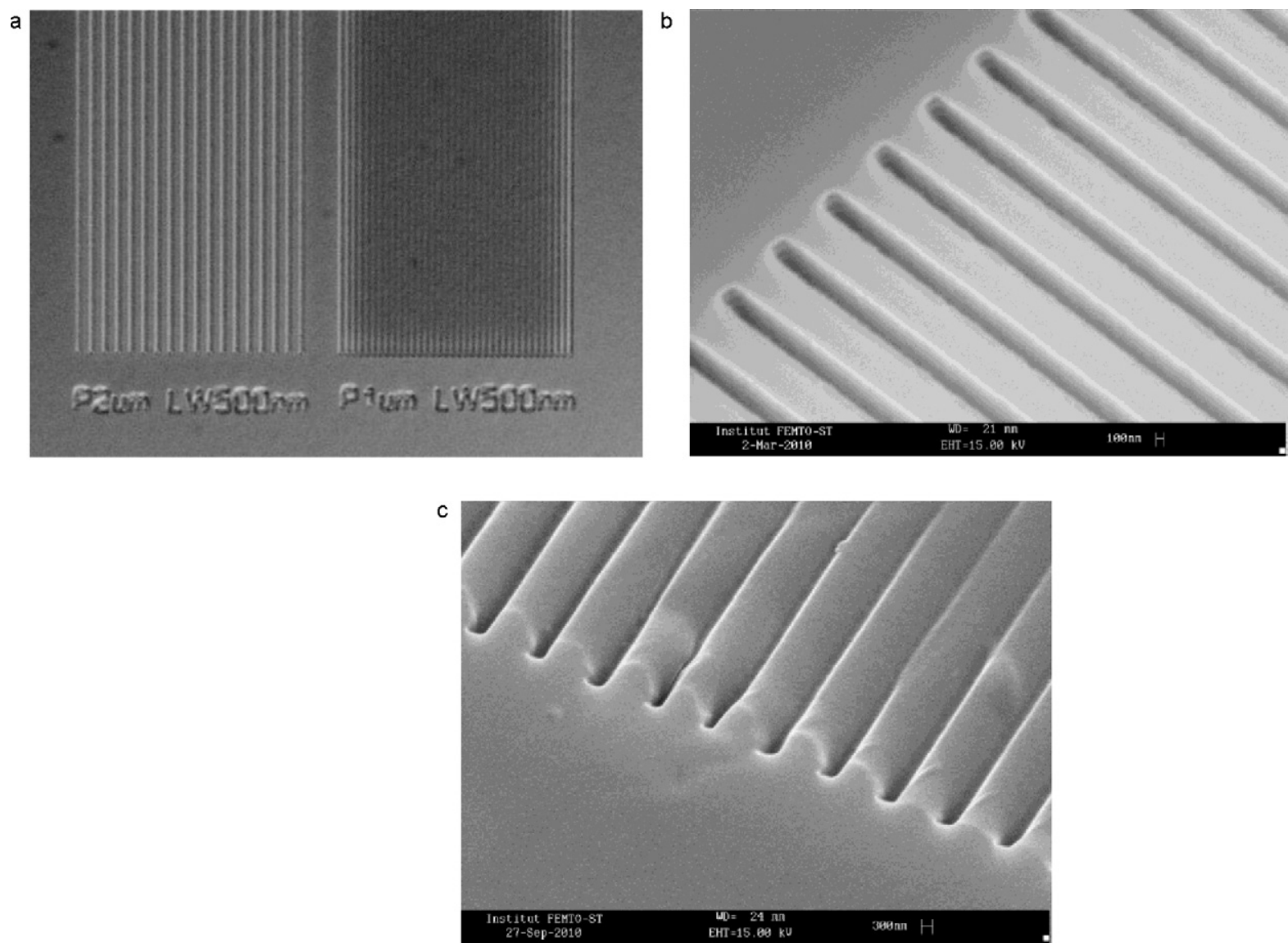

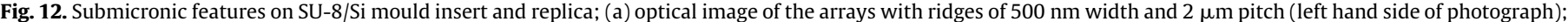

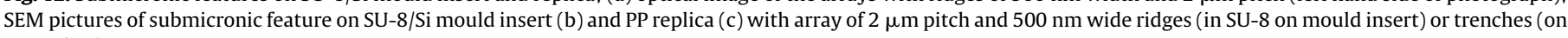
PP replica). 
to hundreds of nanometers using clean room technologies are adapted for prototyping needs and in some cases for small series as well. They are competitive with existing processes targeting the same size range, that is mechanical micromachining or proximal probe writing techniques, respectively.

\section{Outlook}

First experiments of replication of submicronic features have been demonstrated using a SU-8/silicon mould insert produced by ebeam lithography. The same operation conditions were used for injection moulding of submicronic features as for injecting microscopic features. An example of replica with an array of $500 \mathrm{~nm}$ features transferred in PP (Sabic) is shown in Fig. 11 along with a detail of the SU-8/Si mould insert (Fig. 12a and b).

\section{Acknowledgements}

This work was carried out within the framework of the PNANO Programme from the French National Agency for Research (ANR); project "Chip X" - ANR-07- NANO-060-02 and the interministerial fund (FUI) CONPROMI. Support for A. Singh and M. Sahli was provided within this framework.

Christine Millot and Roland Salut are greatly acknowledged for their contribution in the measurements of replicas using SMM and electron beam lithography of SU-8 resist, respectively.

\section{References}

[1] Lorentz, H., Despont, M., Fahrni, N., Brugger, J., Vettiger, P., Renaud, P., 1998, High-aspect-ratio, Ultrathick, Negative-tone Near-UV Photoresist and Its Applications for MEMS, Sensors and Actuators A, 64:33-39.

[2] Bogdanov, A.L., 2000, Use of SU-8 Negative Photoresist for Optical Mask Manufacturing, Proc. SPIE -Advances in Resist Technology and Processing XVII, 3999 (Santa Clara CA), pp.1215-1225.

[3] Edwards, T.L., Mohanty, S.K., Edwards, R.K., Thomas, C., Frazier, A.B., September 2000, Rapid Tooling Using SU-8 for Injection Molding Microfluidic Components, SPIE Micro Fluidic Devices and Systems Conference (Santa Clara, CA), pp.82-89.

[4] Steigert, J., Haeberle, S., Brenner, T., Muller, C., Steinert, C.P., Koltay, P., Gottschlich, N., Reinecke, H., Ruhe, J., Zengerle, R., Ducree, J., 2007, Rapid Prototyping of Microfluidic Chips in COC, Journal of Micromechanics Microengineering, 17:333-341.

[5] Hansen, T.S., Selmeczi, D., Larsen, N.B., 2010, Fast prototyping of injection molded polymer microfluidic chips, Journal of Micromechanics Microengineering, 20:1-8.

[6] http://www.microchem.com/products/pdf/SU-82000DataSheet2025thru2075Ver4.pdf (site consulted in September 2010)

[7] SU-8 website http://www.mit.edu/ 6.777/matprops/su-8.htm (site consulted in September 2010).

[8] Wehbi, D., Clerc, M.A., Roques-Carmes, C., 1986, Three-dimensional Quantification of Wear Tracks on Amorphous NiB Coatings, Wear, 107: 263-278.

[9] Dhouib, K., Khan-Malek, C., Pfleging, W., Gauthier-Manuel, B., Duffait, R., Thuillier, G., Ferrigno, R., Jacquamet, L., Ohana, J., Ferrer, J.L., Théobald-Dietrich A., Giegé, R., Lorber, B., Sauter, C., 2009, Microfluidic Chips for the Crystallization of Biomacromolecules by Counter-diffusion and On-chip Crystal X-ray Analysis, Lab on Chip, 9/10: 1412-1421.

[10] Singh, A., Robert, L., Michel, G., Khan-Malek, C., Microfluidic Biochip Injection Moulded Using a Patterned SU-8/Si Mould Insert, Journal of Polymer Engineering, in press. 